\title{
PENYULUHAN ALAT SPRAYER ELEKTRIK BAGI MASYARAKAT PETANI DESA WONODADI WETAN KABUPATEN PACITAN
}

\author{
Oleh: \\ Elsen Ronando', Enny Indasyah ${ }^{2}$ \\ 1,2 Teknik Informatika, Fakultas Teknik, Universitas 17 Agustus 1945 Surabaya \\ 1 elsen.ronando@untag-sby.ac.id
}

\begin{abstract}
Abstrak
Sebagian besar masyarakat di desa Wonodadi Wetan bermatapencaharian sebagai petani. Beberapa penyuluhan yang terkait banyak dilakukan dengan tujuan untuk mengembangkan sektor pertanian di desa Wonodadi Wetan. Akan tetapi, beberapa penyuluhan jarang menyentuh aspek teknologi tepat guna yang efektif untuk mendukung pertanian di desa Wonodadi Wetan. Salah satu teknologi yang perlu dikembangkan di desa Wonodadi Wetan dalam mendukung pertanian adalah alat sprayer. Pengembangan ini diperlukan karena mayoritas masyarakat petani di desa Wonodadi Wetan masih menggunakan alat sprayer manual. Atas dasar inilah, dilaksanakan program pengabdian masyarakat penyuluhan perancangan alat sprayer elektrik bagi masyarakat petani desa Wonodadi Wetan. Tujuan dari program pengabdian masyarakat ini adalah agar masyarakat mampu melakukan proses perancanaan, perancangan, dan penggunaan alat sprayer elektrik secara tepat. Berdasarkan hasil evaluasi, kegiatan pengabdian masyarakat ini memperoleh respon yang sangat baik dari masyarakat petani di desa Wonodadi Wetan dengan tingkat kepuasan $75 \%$ sangat puas.
\end{abstract}

Kata Kunci: sprayer, sprayer elektrik, pertanian, Desa Wonodadi Wetan

\begin{abstract}
Most of people in Wonodadi Wetan's village are as farmers. Several related trainings were conducted to develop the agricultural sector in Wonodadi Wetan's village. Yet, several trainings rarely hold effectively technology aspect in supporting agriculture in Wonodadi Wetan's village. One of technologies that need to be developed in Wonodadi Wetan's village in supporting agriculture sector is sprayer tool. The technology needs to be advanced because the majority of farming communities in Wonodadi Wetan's village still use manual sprayer tool. Based on this, community service program in training electric sprayer tool design was implemented for Wonodadi Wetan's village, especially for farmers. The aims of community service program were for farmers to be able in planning, designing, and using electric sprayer appropriately. Based on the evaluation, the result showed that the activity has received a very good response from farmers in Wonodadi Wetan's village with the satisfaction level of $75 \%$ very satisfied
\end{abstract}

Keywords: sprayer, electric sprayer, agriculture, Wonodadi Wetan's Village

\section{PENDAHULUAN}

Desa Wonodadi Wetan, Kabupaten Pacitan adalah salah satu desa dengan potensi pertanian dan peternakan yang sangat baik. Sebagaian besar masyarakat desa Wonodadi Wetan memiliki mata pencaharian sebagai petani maupun peternak. Beberapa hasil pertanian unggulan, seperti cengkeh, menjadi komoditas utama di desa ini (pemdes, 2017) .

Beberapa pelatihan yang terkait dengan pertanian maupun peternakan telah banyak dilakukan oleh pemerintah desa dalam rangka meningkatkan potensi komoditas pertanian maupun peternakan (M.N. Rahman dkk, 2014). Namun, beberapa pelatihan yang dilakukan masih kurang berfokus pada pengembangan teknologi tepat guna untuk mendukung pertanian maupun peternakan. Akibatnya, petani maupun peternak masih kurang efektif dalam mengembangkan mata pencahariannya.

Salah satu teknologi tepat guna yang perlu dikembangkan adalah alat sprayer yang digunakan untuk sektor pertanian (G.W. Utomo, 2013). Saat ini, alat sprayer yang digunakan oleh masyarakat desa masih bersifat manual. Sehingga, masyarakat petani desa masih membutuhkan waktu lama untuk menyiramkan pupuk maupun pestisida di seluruh lahan pertanian. Selain permasalahan waktu, intensitas dan jarak penyemprotan air sprayer secara manual 
masih sangat terbatas. Akibatnya kualitas penyemprotan air sprayer menjadi tidak merata (M.N. Rahman dkk, 2014).

Berdasarkan permasalahan ini, alat sprayer elektrik dirancang dan dibuat untuk mendukung pertanian di desa Wonodadi Wetan, Kabupaten Pacitan. Penyuluhan terkait dengan perancangan sdan pembuatan alat dilakukan untuk masyarakat desa Wonodadi Wetan, khususnya masyarakat yang bermatapencaharian sebagai petani.

Dengan wawasan teknologi tepat guna ini diharapkan mampu membantu masyarakat desa Wonodadi Wetan dalam mengembangkan pengetahuan terhadap inovasi teknologi secara tepat. Selain itu, juga mampu memberikan masyarakat desa jiwa kewirausahaan dalam pengembangan alat sprayer elektrik untuk diproduksi secara masal.

Untuk mendukung hal tersebut, desa Wonodadi Wetan Kabupaten Pacitan bekerjasama dengan Lembaga Penelitian dan Pengabdian Pada Masyarakat (LPPM) Universitas 17 Agustus 1945 (UNTAG) Surabaya menyelenggarakan program pengabdian kepada masyarakat yang berfokus pada pengembangan teknologi tepat guna bagi masyarakat petani. Pada awalnya, LPPM UNTAG Surabaya melakukan beberapa kajian terkait masih kurangnya pengembangan teknologi dalam aspek pertanian di desa Wonodadi Wetan. Hasil kajian tersebut menunjukkan adanya permasalahan, yaitu minimnya wawasan masyarakat dalam inovasi teknologi tepat guna dan kurangnya modal. Oleh karena itu, dirumuskan penyuluhan untuk pengembangan teknologi tepat guna dalam bidang pertanian. Tujuan dari kegiatan program pengabdian masyarakat ini adalah untuk meningkatkan pemahaman dan ketrampilan masyarakat dalam pembuatan, penggunaan, dan perawatan alat sprayer elektrik untuk mengembangkan sektor pertanian.

\section{METODE PELAKSANAAN}

Program ini bertujuan untuk memberikan penyuluhan kepada masyarakat desa Wonodadi Wetan, Kabupaten Pacitan terkait dengan pengembangan teknologi tepat guna, berupa alat sprayer elektrik.

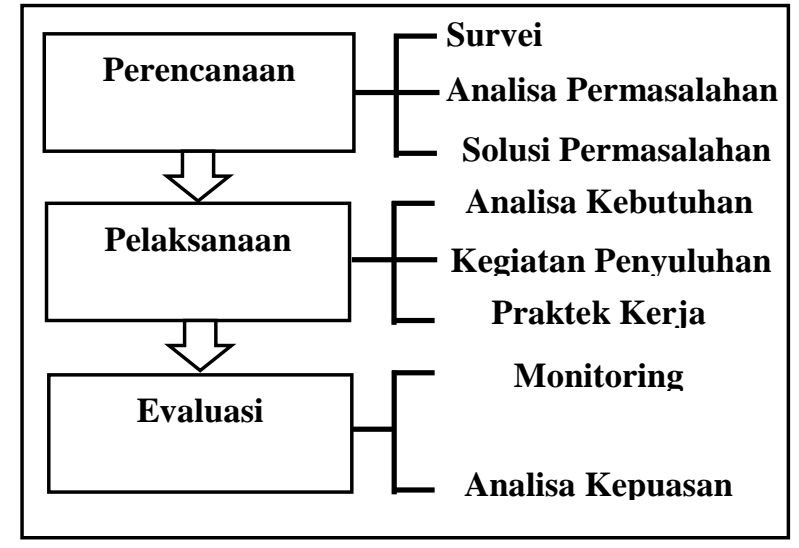

Gambar 1. Alur Metode Pelaksanaan Kegiatan Pengabdian kepada Masyarakat

Gambar 1 merupakan alur metode pelaksanaan yang digunakan untuk mendukung kegiatan ini dengan penjelasan sebagai berikut:

\subsection{Perencanaan Kegiatan}

Pada tahapan ini, dilakukan kegiatan perencanaan sebagai berikut:

a. Melakukan survei terhadap kondisi masyarakat desa Wonodadi Wetan.

b. Menganalisa permasalahan yang ada di desa Wonodadi Wetan, khususnya dengan pengembangan teknologi tepat guna di sektor pertanian.

c. Menganalisa penyelesaian permasalahan yang ada sesuai dengan kebutuhan masyarakat desa Wonodadi Wetan.

d. Melakukan koordinasi dengan LPPM Universitas 17 Agustus 1945 (UNTAG) Surabaya dan kantor desa Wonodadi Wetan Kabupaten Pacitan untuk menyusun program pengabdian kepada masyarakat dalam menyelesaikan permasalahan yang ada.

\subsection{Pelaksanaan Kegiatan}

a. Mempersiapkan kegiatan pengabdian masyarakat terkait dengan penyuluhan teknologi tepat guna, yaitu alat sprayer elektrik bagi masyarakat tani di desa Wonodadi Wetan. 
b. Menganalisa kebutuhan untuk mendukung kegiatan penyuluhan yang dilakukan di desa Wonodadi Wetan.

c. Mempersiapkan bahan maupun materi yang digunakan untuk pendampingan kelompok tani di desa Wonodadi Wetan Kabupaten Pacitan dalam pengembangan alat sprayer elektrik. pengabdian masyarakat tentang penyuluhan alat sprayer elektrik di desa Wonodadi Wetan. Dari hasil monitoring tersebut, dapat digunakan sebagai dasar acuan untuk menganalisa kendala dalam kegiatan tersebut. Selain itu, kegiatan monitoring juga dapat digunakan untuk menganalisa tingkat kepuasan terhadap penyelenggaraan yang dilaksanakan.

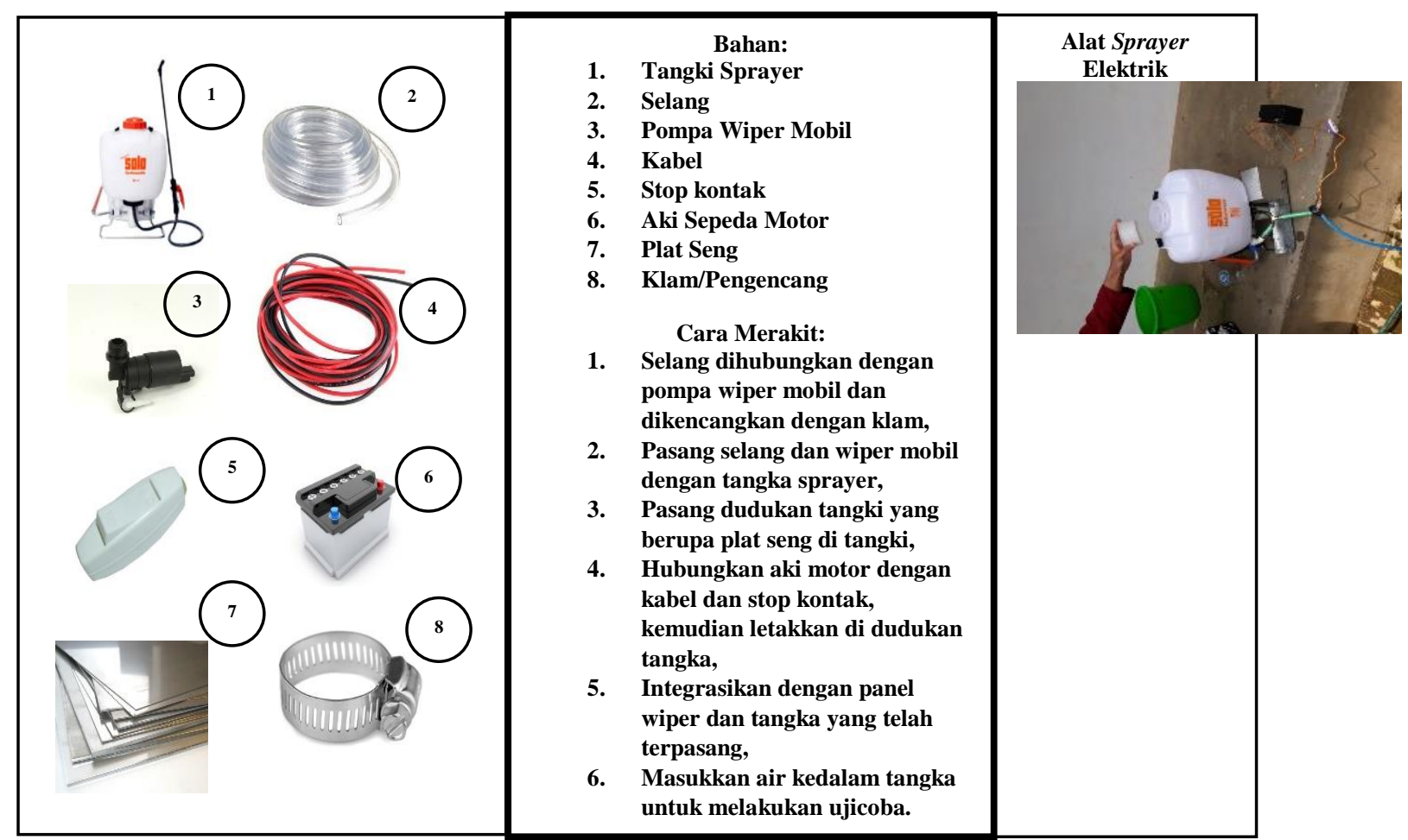

Gambar 2. Bahan Peralatan dan Rancangan Alat Sprayer Elektrik

d. Melakukan penyuluhan teknologi tepat guna untuk merancang dan menggunakan alat sprayer elektrik secara tepat.

e. Menambah pengetahuan masyarakat desa Wonodadi Wetan Kabupaten Pacitan untuk melakukan inovasi teknologi dengan bahan yang ekonomis.

f. Menyerahkan prototype alat sprayer elektrik kepada kelompok tani desa Wonodadi Wetan Kabupaten Pacitan.

\subsection{Evaluasi Kegiatan}

Kegiatan evaluasi ini bertujuan untuk melakukan monitoring terhadap kegiatan

\section{HASIL DAN PEMBAHASAN}

Program pengabdian kepada masyarakat ini dilaksanakan di Kantor desa Wonodadi Wetan Kabupaten Pacitan. Program ini dilakukan dalam bentuk penyuluhan alat sprayer elektrik dalam mendukung pertanian di desa Wonodadi Wetan. Sasaran peserta penyuluhan ini adalah masing-masing dua orang perwakilan dari enam dusun di desa Wonodadi Wetan Kabupaten Pacitan. Sehingga, total peserta secara keseluruhan adalah 12 orang peserta.

Berikut ini merupakan tahapan dari penyuluhan alat sprayer elektrik di desa Wonodadi Wetan Kabupaten Pacitan, yaitu: 


\subsection{Perencanaan Kegiatan}

Pada tahapan ini, dilakukan survei awal terkait dengan teknologi pertanian yang saat ini digunakan di desa Wonodadi Wetan. Diperoleh hasil bahwa mayoritas teknologi yang digunakan oleh petani di desa Wonodadi Wetan masih bersifat manual. Sehingga, hal ini menimbulkan beberapa permasalahan, seperti tidak efektifnya teknologi yang digunakan. Salah satu teknologi yang masih bersifat manual adalah alat sprayer. Beberapa petani di desa Wonodadi Wetan Kabupaten Pacitan terkendala tidak efektifnya penggunaan alat sprayer ini, seperti tidak meratanya hasil semprotan. Selain itu, teknologi ini menyebabkan kelelahan bagi para penggunanya. Oleh karena itu, diperlukan inovasi alat sprayer elektrik yang mampu mengatasi permasalahan para petani di desa Wonodadi Wetan Kabupaten Pacitan.

Berdasarkan analisa permasalahan tersebut, LPPM UNTAG Surabaya beserta kantor desa Wonodadi Wetan Kabupaten Pacitan melakukan koordinasi untuk menyelenggarakan kegiatan pengabdian kepada masyarakat terkait dengan penyuluhan alat sprayer elektrik di desa Wonodadi Wetan Kabupaten Pacitan. Kegiatan pengabdian kepada masyarakat ini diselenggarakan melibatkan beberapa mahasiswa untuk proses pendampingan.

\subsection{Pelaksanaan Kegiatan}

Dalam kegiatan ini, pelaksana menganalisa dan mempersiapkan bahan maupun materi yang digunakan untuk penyuluhan alat sprayer elektrik di desa Wonodadi Wetan. Pada tahap awal, peserta penyuluhan memperoleh materi terkait dengan pentingnya inovasi teknologi tepat guna. Penyampaian materi ini dilakukan oleh Enny Indasyah, S.ST., M.T., M.Sc. Tahapan berikutnya, masyarakat desa Wonodadi Wetan memperoleh penyuluhan terkait dengan perancangan alat sprayer elektrik yang disampaikan oleh Elsen Ronando, S.Si., M.Si., M.Sc. guna menunjang pertanian di desa Wonodadi Wetan. Dalam proses perancangan alat sprayer elektrik tersebut memerlukan beberapa bahan, seperti selang, klam, pompa wiper, kabel listrik, skalar, aki, dudukan pompa, dan tanki sprayer, seperti yang ditunjukkan pada Gambar 2.

Untuk mendukung kegiatan ini, mahasiswa diikutsertakan. Sebelum penyuluhan dilaksanakan, dilakukan pembekalan kepada mahasiswa terkait perancangan atau pembuatan alat sprayer elektrik.

Penyampaian materi terkait alat sprayer elektrik diawali oleh pemateri, yaitu Enny Indasyah, S.ST., M.T., M.Sc. dengan materi terkait pentingnya inovasi teknologi tepat guna dan pengembangan alat spayer dalam mendukung pertanian. Kemudian, materi terkait dengan perancangan dan penggunaan alat sprayer elektrik disampaikan oleh Elsen Ronando, S.Si., M.Si., M.Sc. Setelah seluruh materi dijelaskan, tahapan pelaksanaan berikutnya adalah praktek perancangan alat sprayer elektrik. Pada tahapan ini, mahasiswa dilibatkan untuk melakukan pendampingan dalam perancangan alat sprayer elektrik.

Beberapa peserta penyuluhan sangat antusias dalam kegiatan ini. Banyak peserta menyampaikan beberapa pertanyaan terkait dengan cara pembuatan maupun bahan yang digunakan dalam alat sprayer elektrik. Ini disebabkan bahan-bahan yang digunakan dalam perancangan alat sprayer elektrik sangat ekonomis dan mudah didapat. Sehingga, harga pembuatannya lebih murah daripada alat sprayer elektrik yang sudah ada di pasaran.

Selanjutnya, proses ujicoba alat sprayer elektrik dilakukan. Hasil menunjukkan bahwa teknologi sprayer elektrik ini mampu mengatasi permasalahan alat sprayer manual, yaitu kualitas semprotan lebih merata dan lebih nyaman digunakan.

\subsection{Evaluasi dan Monitoring Kegiatan}

Pada tahapan ini, dilakukan evaluasi terhadap proses penyuluhan alat sprayer elektrik di desa Wonodadi Wetan Kabupaten Pacitan. Tingkat kepuasan masyarakat desa Wonodadi Wetan dalam mengikuti penyuluhan ini dari awal sampai akhir akan dievaluasi. Berdasarkan evaluasi terhadap 12 orang yang mengikuti penyuluhan ini, mayoritas peserta sangat puas dengan kegiatan ini. Grafik tingkat kepuasan peserta terhadap kegiatan penyuluhan alat sprayer elektrik diilustrasikan pada Gambar 3. 


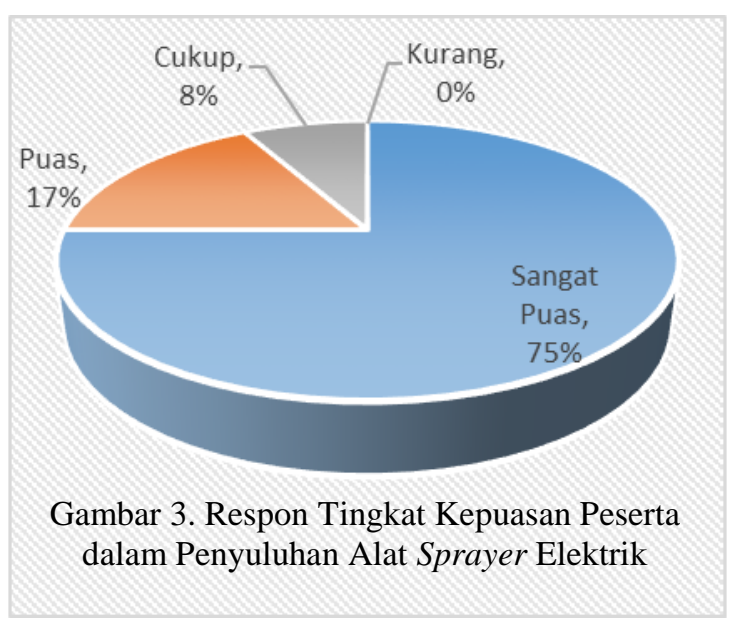

Berdasarkan Gambar 3. diatas, 10 orang dari 12 peserta yang mengikuti penyuluhan menyatakan sangat puas dengan kegiatan penyuluhan yang diadakan. Sementara itu, 2 orang peserta menyatakan puas dan 1 orang menyatakan cukup puas. Dari hasil ini, dapat disimpulkan bahwa masyarakat desa Wonodadi Wetan Kabupaten Pacitan sangat puas dengan kegiatan ini. Meskipun masyarakat desa Wonodadi Wetan sangat puas dan kegiatan ini telah dilaksanakan, proses monitoring atau pendampingan masih sangat perlu dilakukan. Tujuannya adalah untuk mengamati perkembangan alat sprayer elektrik dalam mendukung pertanian di desa Wonodadi Wetan Kabupaten Pacitan.

\section{SIMPULAN DAN SARAN}

\section{Simpulan}

Dengan adanya kegiatan program kemitraan masyarakat tahun anggaran 2017 untuk petani di desa Wonodadi Wetan Kabupaten Pacitan, dapat menyelesaikan permasalahan mitra dengan baik. Secara umum, program kemitraan masyarakat dengan tema penyuluhan alat sprayer elektrik ini memiliki hasil yang baik sebagai berikut:
1. Produk teknologi tepat guna berupa alat sprayer elektrik yang dapat digunakan untuk mendukung sektor pertanian di desa Wonodadi Wetan Kabupaten Pacitan.

2. Peningkatan kemampuan masyarakat desa Wonodadi Wetan dalam merancang alat sprayer elektrik melalui penyuluhan yang telah diselenggarakan.

3. Peningkatan tingkat pemahaman masyarakat desa Wonodadi Wetan terhadap pentingnya inovasi teknologi tepat guna.

\section{Saran}

Dalam rangka meningkatkan inovasi teknologi tepat guna, diharapkan masyarakat dapat mengembangkan teknologi alat sprayer elektrik menggunakan tenaga surya sebagai sumber listrik. Selain itu, semangat wirausaha perlu digalakkan bagi masyarakat desa Wonodadi Wetan agar masyarakat dapat memproduksi masal alat sprayer elektrik dan menjualnya.

\section{DAFTAR PUSTAKA}

M.N. Rahman dan M. Yamin. 2014. Modifikasi Nosel pada Sistem Penyemprotan untuk Pengendalian Gulma Menggunakan Sprayer Gendong Elektrik, Jurnal Keteknikan Pertanian, Vol. 2, No. 1, April 2014.

G.W. Utomo. 2013. Perancangan dan Pembuatan Sprayer Pupuk Elektrik, Tugas Akhir. Juli 2013.

Pemdes. "Profil Desa Wonodadi Wetan". Pemerintah Desa Wonodadi Wetan, http://wonodadiwetan.blogspot.co.id (diakses 28 April 2017). 